\title{
GCU
}

Glasgow Caledonian

University

University for the Common Good

\section{Becoming a hillwalker: incorporating history in understandings of physical activity}

Tulle, Emmanuelle

Published in:

Qualitative Research in Sport, Exercise and Health

DOI:

10.1080/2159676X.2016.1270993

Publication date:

2017

Document Version

Author accepted manuscript

Link to publication in ResearchOnline

Citation for published version (Harvard):

Tulle, E 2017, 'Becoming a hillwalker: incorporating history in understandings of physical activity', Qualitative Research in Sport, Exercise and Health, vol. 9, no. 2, pp. 170-182.

https://doi.org/10.1080/2159676X.2016.1270993

\section{General rights}

Copyright and moral rights for the publications made accessible in the public portal are retained by the authors and/or other copyright owners and it is a condition of accessing publications that users recognise and abide by the legal requirements associated with these rights.

Take down policy

If you believe that this document breaches copyright please view our takedown policy at https://edshare.gcu.ac.uk/id/eprint/5179 for details of how to contact us. 
Becoming a hillwalker: Incorporating history in understandings of physical activity

\begin{abstract}
This paper challenges dominant explanations of physical activity participation in later life as they tend to prioritise individual motivation at the expense of other explanations. Reference is also made to generational characteristics. What the recourse to generation tends to do is reinforce stereotypes of age, while the more complex and deep-seated processes which affect the development of dispositions to physical movement are not highlighted. Furthermore the conditions in which physical activity can be maintained throughout the lifecourse are occluded. I propose therefore that we should recast physical activity participation within the context of a history of appropriate and normative physicality acting as a weight which infuses whether and how we develop physical activity as a durable practice. In the process I will adopt an eclectic theoretical stance. To bring the complexities of physical activity participation to the fore, I will focus on my own experiences of a particular type of physical activity: hillwalking. I will make the case for a critical autobiographical approach to show how important history has been in the awakening of my physical dispositions and in the long journey of identity formation. I conclude that we can conceive of obstacles to physically active embodiment as manifestations of oppression rather than as a question of individual motivation.
\end{abstract}

Keywords: physical activity, embodiment, career, gender, age

\title{
Introduction
}

The attention given to physical activity, in particular for older people, has been exploding in academic writing and most especially in the life sciences. This literature has interfaced with global anxieties about the costs associated with population ageing and is beginning to attract an audience among policy-makers increasingly convinced that physical activity will be an effective response to what is often termed the burden of ageing: increased costs to health and social care systems as a consequence of agerelated illness. Whilst there has been great success in convincing policy-makers, there has been less in getting older people to act on this new knowledge. Physical activity participation figures remain steadfastly stuck at around $20 \%$ for people aged 60 and over, with women less active and more sedentary than men (for Scotland and the US 
see (Campbell-Jack et al., 2015; Carlson, Susan A., Fulton, Janet E., Schoeborn, Charlotte, E., Loustalot, Fleetwood, 2010).

The challenge is to understand why older people are apparently so reluctant to take up physical activity. The argument which I will develop in what follows is that there are fundamental gaps in how people's 'failure' to be physically active is understood and analysed. The sports medicine and sports science literature from which most pronouncements about the physical activity deficit in later life emanate assumes that there are age-related differences and similarities which constitute the very essence of being old now, as a homogeneous experience. For instance, in their revised recommendations, the American College of Sports Medicine (ACSM) states that 'older populations are generally less physically active than young adults' (ChodzkoZajko et al. 2009: 1512). Yet ACSM also finds that some older people have levels of activity that 'may approach those of younger normally (my emphasis) active adults' ( $p$ 1512). This suggests that there is variability within generations. In addition the turn to physical activity in old age is a very recent development - physical activity recommendations only began to appear in the 1990s (Mazzeo et al., 1998). Hitherto, the disintegration of the ageing body had been taken for granted and normalised. Ageing bodies had been understood within a discourse of decline which constructed physical decrements as inevitable. Within this frame, at best gentle exertion was recommended, not vigorous physical activity (Gilleard and Higgs 2013). Thus current recommendations represent a major turnabout in orthodox approaches to aged embodiment: physical activity must now be a normal part of later life. The response from the sports science and sports medicine literature has been to develop interventions designed to ensure that older people meet physical activity recommendations (see Chodzko-Zadjko et al. 2009, World Health Organisation 2010), so far with little significant success.

I contend that this is because current analyses of why older people 'fail' to be physically are flawed and lack critical depth. In response we need to start thinking about intervention from different premises, in ways which reflect the complex processes which govern how we put our bodies in movement. I propose that our orientations to physical activity are the outcome of historical and structural forces which are deeply laid down in our bodies, inform our habitus, ie our social location (Bourdieu 1984), and extant dispositions to be physically active and, more fundamentally our identity as physically active or otherwise. To flesh out this 
complexity I will focus on a case study: a critical biographical review of my own experiences of becoming a mountaineer as a midlife woman, wife, mother and academic with little foresight and few hints of what lay ahead, at least in the first years of my involvement. In particular I will explore how what I conceptualise as the weight of history has, over the last 30 years, shaped and almost derailed the actualisation of a hillwalking career, contributed to the emotional implications of making choices and most notably forced me to confront head on deeply embedded norms of appropriate feminine physicality.

\section{Thinking sociologically about physical activity}

The dominant narrative of physical activity intervention, despite some valiant efforts to broaden out to environmental (Ward Thompson et al. 2014) and ecological models (Owen et al. 2010), places the individual at the nexus of concentric circles of influences, at once victim and volitional agent, deprived of the motivation to exercise (e.g. (Dobbins et al. 2013, author 2015). As there has been little evidence that physical activity interventions are effective (Hawley-Hague et al. 2016), I contend that we need a new approach in how we capture the conditions in which people become physically active, away from a language of motivation with its focus on individual responsibility as a moral obligation (Baars 1991) towards a more critical and fine-tuned approach.

In the main the social science literature paints a complex picture of older adults who already exercise, with sport as a source of social connection, of identity, as an opportunity to display competitive spirit (Dionigi, O'Flynn 2007) or from which to derive pleasure (Orr, Phoenix 2015). This takes place within the dominant discourse of ageing, which has shifted from an understanding of ageing as inevitable, inexorable decline to one of decline management or even avoidance as obligation (author 2015), with exercise reframed as an anti-ageing practice (author 2008). It is also in tension with the experiences of those who are more reluctant exercisers. In a study of people who attended a post cardiac rehab exercise class, which also welcomed people with other pathologies such as osteoporosis, I (author 2012) drew attention to the class participants' perceived fragility of their bodies. They found themselves caught up between the need to manage pathology and the encouragement to improve their physical performance and the fear of over-doing it. They rejected a sporting identity 
not because they did not want it but rather because they did not conceive it as part of their sense of self or as something that could be developed or even as a process that their bodies could withstand.

Dionigi (2015) has shown that older exercisers mostly fit within three groups: rekindlers, continuers and late bloomers. These typologies are captured from the vantage point of the present, as having already come to pass. What is made less explicit are the complex processes through which people encounter physical activity. This means giving greater attention to the ways that our biographies intersect with history (Pilcher 1994) in our understandings of how people become physically active as their lives unspool, taking account of the actual rhythm of individual lives as they meet the changing urgencies of society - such as the discoveries by policy-makers of the putative health and anti-ageing benefits of physical activity. Indeed Muldoon (2006:17) writes that "every action is the result of a temporal synthesis based on our body's ability to register impressions, process them, and act appropriately." Furthermore, as 'time [is] lived' (Muldoon 2006: 19), there is no knowing that what we undertake to do will stick.

What I am advocating therefore is an approach to understanding how people become and remain physically active which embeds time as a core component. The conception of time I have in mind is experiential time, time which captures the complexities and multiplicities of individual lives, subjective experiences which are continually created in the present (Adams 1990), digging deep into lives and bodies to unearth the remains of historical influences.

\section{The Weight of History}

In understandings of later life and social change, we often have recourse to two concepts: cohort and generation. They help us make sense of historical change by charting the ontological characteristics of successive groups of people, to interrogate what makes them distinctive in ways which reflect distinctive sets of values and behaviours by which these groups would recognise themselves. This work of clarification was undertaken by Mannheim (1970) in his sociological analysis of generations. A generation might exist when external events bind people together and they are conscious of what Mannheim (1970: 395) himself called a 'generation as an actuality'. But it is also the case that 'generations are in a constant state of interaction' (p 392). In her critical appraisal of Mannheim's analysis (1970), Jane Pilcher (1994) 
noted that it is difficult to set neat cut-off lines between groups of people born successively and attribute distinctive sources of identity that would produce an identifiable generation. Nevertheless, implied in Mannheim's work is the recognition that we belong to a specific, identifiable generation that must be felt cognitively but also physically and emotionally. These three elements of generational ontology - the actuality of a generation, its interactions and overlaps with generations past and in becoming and its phenomenological dimension - must be borne in mind when we describe the characteristics and motivations of particular groups of people as they are not only present at a particular historical juncture, but their bodies too bear the marks of their presence at the confluence of several historical influences. They are bodies with memory. Ironically when they try to entice people from older generations to be physically active for health, physical activity advocates are constructing the very differences that they would like to eliminate (Timonen, Conlon 2015).

Thus, to understand why older women do not exercise, one must go beyond noting that they belong to cohorts of women for whom physical exertion would have been alien and that we can design interventions which magically change this. These women embody a set of dispositions - physical and emotional - which is expressed against the backdrop of structures which are themselves historically weighted. Furthermore medical evidence has in the not so distant past pointed the other way: Whorton (1982) described the disagreements which raged in the nascent discipline of sports medicine between 1870 and 1920 about the impact of athletic endeavour on cardio-vascular health. This has added to the confusion about what appropriate aged embodiment is. To sum up so far, what begins to emerge is that we become embodied and this process of becoming is inflected by a range of influences which operate throughout the lifecourse. Even if we take up physical activity at any point in the lifecourse, there is no guarantee that we will remain so for the duration or that its meaning will remain fixed. Therefore we need to turn to the concept of career to bring to visibility how one becomes physically active, the extent of planning that remaining physically active requires, how we become familiar with the field of the activity of which we have become a part, and what labour of identification is entailed.

\section{Physical activity careers}

The concept of career (Becker, Strauss 1956) has been used in sport social science to conceptualise the processual and time-bound aspect of becoming a sports professional. 
It points to the presence of key staging posts which punctuate and structure the process of becoming. It also captures the in-depth engagement with the minutiae of athletes' conditions of existence, for instance organisational cultures but also specific bodily requirements (Heo et al. 2012, Roberts et al. 1991).

The concept of career can be used as a heuristic device (Palmer 2015) to account for behaviours such as informal physical activity or serious leisure (Stebbins 2014) by making explicit the experiential, sensate and historical processes which promote or hinder the take up of a physical activity as well as its maintenance over decades. I have shown in my own work (author; author) that what triggers an action may be transformed later by the very involvement in the action itself with new dimensions of experience discovered. This includes the sensorial and haptic aspect of the body in movement. Nettleton's (2015) research on fell runners and Allen-Collinson's (2010) auto-phenomenographic analyses of her running are good examples of this, procuring rich and complex experiences generative of alternative understandings of what it is like to be physically active.

The re-shaping of embodiment itself is imbued with and shaped by biography and history. Our ability to embark on a physical activity career, especially in our later years, involves a fundamental re-writing of our lives in the context of history. For Merleau-Ponty (Dastur 2001, Merleau-Ponty 1964) the past is not expunged from the present, on the contrary it continues to exist in the present, giving it consistency and shape. It is in this intersection of biography and history that we ourselves are shaped and can conceive of making any changes to our lives (Barral 1984).

\section{The potential for social change}

What ultimately is at stake is change, at the individual and socio-cultural levels. According to Bourdieu (1984) our bodies are the fleshy manifestation of our social location or habitus. We are more likely to develop physical dispositions which are consistent with our habitus. Habitus is like a grid of values and within this grid some bodies have more value than others. It is the extent to which we conform to or deviate from what Bourdieu referred to as bodily hexis (Bourdieu 1992), that is normative embodiment, which situates us. Thus we cannot expect people easily to internalise norms of embodiment which are at odds with the norms embodiment which prevail in their social location. There might even be a price to pay for doing so -disbelief, stigma or accusations of being déclassé or arriviste, depending on the practice 
targeted by the social actor. Challenging age- or gender- appropriate embodiment, especially as it intersects with class, can pose equivalent difficulties. Thus Bourdieu's work reminds us that how we become embodied is constrained. However there might be opportunities for change to modalities of embodiment.

I suggest that we are at a juncture which offers opportunities for rewriting dominant narratives. Gilleard \& Higgs (2013) argue that the contemporary world has loosened norms of aged embodiment. Attracted by the prospect of longer, healthier lives, and encouraged by the promise that this can be achieved with fitness regimes, ageing social actors are able to challenge what are now constructed as outdated norms of embodiment. The conditions are right for what Rose (2007) calls a new form of life, that is a live re-writing of our biological selves. For others, this represents a false challenge to ageing by normalising a new culture of agelessness (Andrews 1999). Correspondingly Markula $(2003,2006)$ has reflected on how women can perform athletic embodiment without rewriting it as quasi masculinity (where women would therefore always fall short) or reverting to dominant norms of feminine embodiment. The female runners I interviewed several years ago (author 2008) fitted this model of life transformation and the process had required doggedness, imagination but also the assent of their male partners. It had taken years and they were remarkable by deviating from the norms of feminine embodiment and dispositions. Nevertheless the extent to which they could run freely had been predicated on gaining permission. These theoretical, empirical and ultimately practical dilemmas are about the possibility and type of social change that can be ushered in, one that is not a pale copy of a dominant reality but its rewriting, challenging class, gender and age norms. The search for alternative narratives has led me to consider my own personal experiences as they have developed over time in order to illuminate broader social and cultural processes. Allen-Collinson $(2010,2011)$ has used her sensate experiences to capture the fluctuations in her own sense that she had a legitimate right to run in public spaces. She tells of her 'habit-running body', acquired over a 24-year running career being regularly disrupted by external intrusions (verbal and physical threats from men). During one particular incident she became frightened, needlessly as it turned out. However the experience was memorable enough that it forced her to consider what it is like to run as a woman, and how she would maintain her freedom to run whilst remaining safe. 
To fully understand Allen-Collinson's experiences we need to see them as located at the intersection of the biographical and the historical, of the diachronic and the synchronic (Bourdieu 1984). In this way we can foreground the ways in which gender and age norms give shape to a life as it unspools. We can also explore how prone to being challenged these norms are, what personal price is paid or riches gained in the process. In doing so what we are seeking is evidence of the emergence of new modalities of embodiment which might open the way to resistant embodiment and a broadening of our imaginings of agency. As Archer (2012) has shown, this broadening means delving into the interior life, the silent dialogue that takes place in our encounters with those who intersect and sometimes accompany us on our life journeys. Often we do not know what we have accomplished until we look back, sometimes quite far back, and these backward glances are what enable us not only to measure what we have achieved but also to articulate explanations for how we got there. The following questions therefore emerge: how has a hillwalking career been allowed to emerge? What historically grounded sediments have been exposed to account for the fits and starts of this career? Is there a distinctive way of walking which transcends the historically bounded limitations enfleshed in normative feminine and aged physicality?

\section{A Sociological Analysis of Life}

To be able to identify and track the role of historical influences in the shaping of physical activity careers requires an appropriate approach to research - one which delves deeply into lives and the narrations or stories that people think reflects the shape of their lives (Erben 1998). In previous work I have experimented with life history interviews to understand the lives of others (author 2008). I found these particularly useful to examine the interaction between individual idiosyncracies and a range of historical, cultural and structural influences. On this particular occasion however I wished to go further and access the interior life as well the layering of influences that have shaped the development of a physical activity career, so that I could understand how exactly decisions had been made. I therefore elected to subject my life, myself and my hillwalking practice to systematic sociological scrutiny. I set out to dig out 'the multiple layers of consciousness, connecting the personal to the cultural' (Ellis, Bochner 2013). My aim was to understand how achievements and shortcomings have played out against the longue durée of history, highlighting the 
points of anchor in a lifetime upon which historically and structurally significant events, processes, conventions, expectation, dispositions and discourse have become hooked like chains, weighing down and shaping the course of this (my) life, at the same time giving my life coherence through personal narration (Ricoeur 1992). The material body can be incorporated into the life review (Sparkes 2015) as the bearer of these chains and thus the generator of decisions and actions. I am aware of the personal risk I am taking in making aspects of my personal life public. However the impetus was not a narcissistic undertaking per se but a critical examination, identifying the conditions for the development of a practice, the emergence of an identity and consciousness as a mountaineer and getting into the logic of the practice to expose the real obstacles - emotional, physical and historical - which have weighed and shaped the life as it unfurled.

To this end I used a combination of auto-ethnography and life review (Plummer 2001), in order to produce a critical autobiography, a narration of my life and experiences which would challenge normative, and I would argue superficial, understandings of behaviour. Unlike in auto-ethnography, I did not consciously or systematically keep notes of my walks until 2014 and these are in the main descriptive accounts of route findings, the contemplation of views and the recognition of the landscape (hillspotting). Before then I had not envisaged that my hillwalking would become a focus of sociological reflexion as I considered it an activity belonging strictly to the personal realm. Not a natural diary-keeper, my impressions and the issues arising from them were mostly stored internally, occasionally articulated in verbal exchanges with regular walking partners and sympathetic significant others. Because I have walked since 1994, these impressions and issues have been a constant backdrop to my practice and over the years I have come to understand their wider significance, not only in personal terms but also in sociological terms.

As a constellation of reflexions they have begun to inform a set of extant analyses on how we take up and maintain physical activity, particularly as this applies to older women. In other words, my personal experiences can be seen as 'instances of a more general state of affairs' (Chisholm 2008). Ultimately although I did not systematically record my experiences, I lived through them repeatedly and they have become etched in my bodily and psychic make-up, literally embodied and manifested in my current orientation to how I work at being a hillwalker, a time-rich process. During the process of critical review, several strands emerged which connected to one story: the 
emergence, durability and at the same time the fragility of a hillwalking career. They enabled the story to make sense but also corresponded to analytical themes. Therefore I have bracketed out (Allen-Collinson 2011) three themes which have emerged in the course of my personal reflexions informed by an interpretive intent: 1. Encountering the hypermasculine world of hillwalking, 2. The fragility of a hillwalking career and 3. Being a woman hillwalker. An understanding of the relevance of these themes requires a brief history of mountaineering in Scotland.

\section{Mountaineering in Scotland}

Mountaineering or hillwalking in Scotland reflects a historical trajectory in which gender and class play a key albeit ambiguous and fluctuating role. Scotland's mountains have provided the training ground for many early British mountaineers. Although not as high as Alpine ones, Scottish mountains nevertheless present significant challenges in terrain and weather conditions. For instance the north side of Ben Nevis has rock and ice climbs which rank high in difficulty. The Cairngorms is the highest and largest wild land in the UK and experiences arctic weather conditions. Scotland's mountain environment is also largely undeveloped and therefore constitutes the largest area of wild lands in Britain (http://cairngorms.co.uk/discoverexplore/facts-figures/).

The highest UK mountain, Ben Nevis stands at $1393 \mathrm{~m}$ and is one of 282 Munros. Munros were named after Sir Hugh Munro who identified and listed them in 1891. To qualify as Munros, mountains have to be 3000 feet in height or higher with 'sufficient separation' between peaks to warrant the mountain appellation (http://www.smc.org.uk/hillwalking/hill-lists). Since the compilation of the list, the pursuit of 'Munro-bagging' or Munro-ticking has developed and the number of people who have completed the whole round of Munros (or 'compleated) stands at over 6,000, according to the register kept by the Scottish Mountaineering Club (http://www.smc.org.uk/munros/MunroistsCompleatists.php). There are some records, such as completing the whole round in winter or summer in the shortest time, or the most number of rounds. Lower hills have also been listed and there are equivalent appellations with height criteria such as Corbetts (all 'tops' above 2,500 feet), Grahams (all summits above 2,000 feet), and a few others (http://www.mcofs.org.uk/munro-corbett-introduction.asp). Some hillwalkers also endeavour to complete these rounds. More recently, long distance walking routes 
have also been created, the pioneer being the West Highland Way, which is 94 miles long, to which have been added the Speyside Way, the John Muir Way, the Cape Wrath Way, etc...

Early mountaineers, belonging to the class elite of British society, formed the Scottish Mountaineering Club. In informal histories we learn that in the decades before WW2, the class profile of mountaineers changed when working class people, mostly male, started escaping from industrial and urban environments to explore the hills of Scotland (see for instance http://www.strathblanefield.org.uk/Craigallian\%20Fire/FireStories.htm). Their new found enjoyment of the hills led to the creation of Hillwalking clubs such as the Glasgow Hillwalking Club. These working class men were joined by a few women. However for women gender as well as class norms had been a key structuring factor (Mazel, 1994). The Scottish Ladies' Climbing Club, at its founding in 1908 (vhttp://ladiesscottishclimbingclub.org/), had a strict access code. Its membership continues to be restricted to women who are competent and experienced. However in the last few decades other groupings have appeared and 'hillwalking', as it is most commonly called, is becoming a mass sport attracting men and an increasing proportion of women. In 2012 women constituted a fifth of Munro compleaters (http://www.smc.org.uk/downloads/munro-matters/munro-matters-2012.pdf). As already noted the mountaineering literature is male-centric and reflects the hypermasculine profile of the practice since it emerged in the $18^{\text {th }}$ century (Hansen 2013, Ortner 1999). Compared to men mountaineers, few books have been written about or by women mountaineers, although the coming to attention of talented female alpinists has been helped by their rarity, often in popular books written mostly by men! Nevertheless, whilst more women take part in hillwalking than ever before, and despite the profusion of blogs and Social Media outlets, women are also underrepresented, their voices and exploits less well showcased than those of men. This is compounded by the tacit hierarchy which exists in mountain sports, with practices involving greater physical danger being male-dominated (Ottogalli-Mazzacavallo and Saint-Martin 2009). It is in this context that my own experiences can be understood. Thus the first theme that presented itself to my analysis is how I, as a woman, entered the hypermasculine world of mountains.

\section{The hypermasculine world of mountains}




\section{Points of entry and re-entry}

Men played a key role in the development of my hillwalking career, and they have informed its course: from first introduction, to restart and its unfolding over the years. I was introduced to walking up mountains when I was 18 years old by my then boyfriend. He organised the trip to the Parc des Ecrins in the French southern Alps, advising on gear, choosing the destination, sorting out train tickets. I do not remember taking much of an active role except when we went to buy the equipment using my parents' money. Although a frequent visitor to alpine environments (I learnt to ski at a young age), I struggled to walk at altitude, I found the rucksack heavy on my slight frame, I suffered from cold hands and I was quite scared of heights. Thus I felt incompetent, devoid of natural aptitude, an issue to which I will return. We did not achieve all the summits he had planned on reaching, although we did summit a 4,000m mountain (Barre des Ecrins). We returned to the same place the following year and I showed improved competence. Before the third trip took place, the relationship ended, and, with it, my mountaineering career.

However these experiences left an indelible mark on me - of what might have been but I did not know how to continue on my own and it took another 12 years before another chance to restart my involvement with mountaineering came up, this time in Scotland. By then I was the mother of an 18-month-old child, married 10 years, working full-time in my first academic post. A colleague who was a self-professed Munro-bagger inaugurated departmental hillwalks.

At first they were well attended. But over time the other women in our group stopped coming and I ended up walking mostly with men, encountering mostly men on summits, reading books about Scottish hills written mostly by men, with the exception of one (Gray 1991), and buying equipment in specialist stores mostly from men. Even the act of putting a tick beside the new Munro on the list at the back of the book to record that it had been successfully ascended was a mostly male-centric gesture. I also experienced resistance from other men and women when I practiced navigation during some walks.

Over time I have walked mostly with a third male friend, developing a very trusting partnership about navigation, and I learnt a lot from his longer experience of this particular mountain environment. Four years ago, I decided to go out into the hills on my own. I had made one attempt a few years previously in challenging conditions (see later). This experience made me pause to consider my skills or the wisdom of 
going out on my own. However I was falling behind my friend's tally and I needed to catch up to have any chance of completing the list. He thought nothing of going out on his own when I was unavailable for walking, being single minded and selfsufficient. He also had a very encouraging wife. It took me 10 years to emulate this approach.

One morning I parked my car in Glen Etive and I headed alone for Beinn nan Aighenan described in the book as very remote. The walk passed without incident, in cold crisp weather. It was not particularly difficult, nor did it seem inordinately lengthy at 7 hours. I sped back home through Rannoch Moor listening to music, feeling confident. This signalled a development in my walking career, its extension to solo walking, and over time I became more adventurous, occasionally going away overnight for multi-day trips and even wild camping.

Whilst I have met many solo male walkers, I have only met one solo woman out walking, in the 90+ Munros I have climbed on my own. I have met none in any of the hostels at which I have spent the night. From my own observation, in mixed groups, women rarely lead and in heterosexual couples, they never do. Thus although there are increasing numbers of women who 'compleat' (ie finish) the Munros, some of whom must walk on their own, I personally have rarely encountered them.

What I have shown so far is that the mountain world that I encountered was a maledominated field, not just in terms of the numerical dominance of men but also in terms of the prevailing culture and the imaginings of how a hillwalking career ought to unfurl. Sometimes women enforced norms of dominant masculinity by pulling out, walking only with other men or not trusting other women to lead them safely. I subscribed to this model when I failed to pursue my mountaineering career by myself for many years. Thus for women the hypermasculine world of mountains shapes opportunities for the development of a career - formal or informal - making their hold on this world fragile. There are of course other factors which weaken this hold and I now turn to the consideration of these factors.

\section{The Fragility of a Hillwalking Career: Emotion and identity}

In this section I want to draw out the lived and sensate nature of building a hillwalking career. Being married and having a young child affected the frequency with which I could go out. Although no interdiction was ever explicitly articulated, I sensed that my outings were deemed too frequent and guilt crept in. I felt I had 
become a wayward child, a development which I did not know how to manage, emotionally or in practical terms, and which I resented.

The other potential threat to a hillwalking career is one that lies at the boundary between the sensate and the rational, in the realm of ontological questioning: what is the point of hillwalking, of ticking mountains off a list, of prioritising these outings over other activities? Was I being selfish? I used to experience these doubts when I was around people who had no interest in the Great Outdoors. In contrast there are many documented examples of male mountaineers who leave partners and children to seek adventure into high mountains, frequently never to return (Coffey 2003), without being apparently over-burdened by such questions. When I am away from the hills for any substantial period I begin to feel a deep sense of loss manifested most clearly when I avoid looking at photographs of mountains as they give me feelings of being out of kilter, of missing out. These are sensations which I can articulate to the unitiated intelligibly only by using the language of identity.

Identifying as a mountaineer, hillwalker or Munro-bagger implies that one owns the activity as a legitimate pursuit and label. However for a long time I would say that I went hillwalking. I rarely claimed that I was a hillwalker, less so a mountaineer, although I did admit sometimes to being a Munro-bagger when asked by others. Several reasons underpinned this coyness or uncertainty about my status, manifested in preferring to describe what I did rather than what I was. Two inter-related elements in particular have influenced me. The first is about the distinction between mountaineering and hillwalking. The difference appears to be based on an incremental level of difficulty and the reliance on equipment. According to the specialist literature (see for instance http://www.mcofs.org.uk/mountaineering.asp), mountaineering refers to the practice of ascending prominences which require the use of technical equipment in challenging weather conditions. Thus a summer hillwalk can become a mountaineering expedition in winter if the use of crampons is required to move efficiently in snow. By the same token getting caught up in a whiteout in summer can also turn a hillwalk into a mountaineering event because the use of navigation skills is required. This differentiation contains an inherent hierarchy of value which historically has been inflected by class and gender (Hansen 2013). Aware of the distinction, I have been very shy about calling myself a mountaineer, despite owning crampons, an ice axe and other technical equipment and being proficient with a map and a compass. When I think of mountain guides or famous 
mountaineers, I find the distance between their practice and mine too large to deserve the label. It is not until I started going out on my own regularly that I started feeling confident about calling myself a hillwalker. When I go out with a new group, I still feel anxious that I will not measure up to their skills, and I tend to minimise my achievements.

All this is at odds with the realisation that when I am out in the Scottish mountains I become caught up in the logic of the practice itself (Bourdieu 1992) and have skills at least equivalent to others. Now it is the value of my achievements as a woman hillwalker which warrants examination.

\section{Dealing with the walks: resisting normative embodiment}

When I was growing up in France in the 1960s and 1970s beliefs about physical competence, that you either had an aptitude for an activity or you did not, were inculcated in me mostly by the women in my family and reinforced at school. This meant that if on first trying a new activity you did not show ability, especially as a female, there was probably no point, or at least no encouragement, in persisting. I was also socialised into a very Cartesian approach, where the care of the body should be subordinated to the development of the mind. This reinforced the message that bodily aptitude was not susceptible to development and that a concern for the body was not part of the dispositions which my parents wanted me to develop.

In hillwalking questions about physical competence (fitness but also the ability to deal with difficult weather conditions) are salient, as are issues about navigation, confidence and problem-solving. For instance, in the last 15 years I have started outpacing my male partner (who is similar in age) and I have caught myself being quite competitive. I have also experienced situations which required assessing and taking risk, by the careful harnessing of reason and emotion. There are two notable examples.

On the first solo walk I mentioned earlier I found myself in a whiteout. I reached the summit of Meall Corranaich without too much difficulty. Although the conditions were tough, windy, without visibility and cold, after some deliberation about the wisdom of continuing, I felt I could handle going to the second summit, Meall a'Choire Leith. This meant heading almost due north. I worked out that in the event of getting lost I would just set my compass to west and I would eventually reach the road. I started walking holding map and compass. As well as my compass bearing I 
followed footprints in the snow. However I lost sight of these and although I was on a ridge connecting two summits, I appeared to be walking down and north east, which didn't seem right. I was peering at the map to understand why, when it blew away. After a moment of panic, I set my compass to west, started climbing to a summit I had not expected, found a line of cairns going down a wide slope, a faint path, and ended up exactly back at my car. I was safe but with one Munro unclimbed.

In 2013 I decided to walk along the Five Sisters ridge in Glen Shiel, an iconic hillwalk which normally requires two cars because of the distance of several miles between the starting and landing points. I had planned to do another walk when a guy at the youth hostel offered to drop me off at the start of the walk. The forecast was exceptionally favourable. Unable to resist the opportunity that offered itself to me, I hastily prepared a route, which meant familiarising myself not only with the general orientation of the hills to be climbed but also their idiosyncracies. The guy had used a different landing point the day before so we guessed that the end point that the route description referred to was at a layby in which another car was parked. It all looked very promising. I set off, moving very quickly to make sure I had enough light to get back to the footbridge across the River Shiel which would allow me to reach my car. I could not see a path off the ridge as I had expected and so took a compass bearing from a point which I estimated was east of the wooden bridge I was aiming for. This took me down perilously and awkwardly steep slopes. I eventually came into view of the bridge only to find that it was broken and impassable (it was damaged in a storm a few years earlier, which my book predated). There were only two options open to me - to go back partway up the hill to traverse along to the village of Shiel Bridge, a mile to the west of where my car was parked or... swim across the burn. I chose the swim: the water was placid and was likely to be at its warmest in September and, more tantalisingly, I could just see my car. I found a suitable spot from which to launch across the 7 or 8 metres of brown but calm water which separated me from the other bank, stored bulky clothing and boots into my rucksack, not knowing whether the weight would make me more or less buoyant, put the bag on my back, stepped down and went into the water. After a few breast strokes, when I was halfway across the burn, that is only a few seconds into the swim, I felt the sharp cold of the water gripping my chest. I took a deep breath to compose myself, swam on and within a short period I was safely on the other side, with a foot resting on a sandstone close to the bank and a dead tree providing a lever to hoist myself out of the water. Within 
seconds I was out of the river and only a few steps later unlocking my car, dripping wet.

I took these risks, not because I had no other options. On both of these occasions I was acutely aware that I was a woman, and in the second event an older one at that, and that making these choices represented a challenge to what others would think was sensible and gender appropriate behaviour. I was challenging myself - that is my navigation skills, my ability not to lose my nerve, my endurance, my experience, my physical capital and of course my decision-making ability - precisely to exercise choice, even if in the process I would get it wrong. Freedom lay in these moments of uncertainty and rash decisions.

\section{Reflexions}

Popkewitz (2013:91) said that 'our personal projects are no longer significant as individual events but are enmeshed in conditions that have social boundaries and plausibility structures through which we construct our possibilities.' What he means is that our lives are inflected by our idiosyncratic everyday choices, serendipitous events, accidents, social structures and also by history.

In this paper I set out to show that to understand why people struggle to be physically active, we need to shift our gaze away from an exclusive focus on behaviour towards a much longer range so that we grasp our actions as having been infused by influences which have their roots much further back than our own lifetime. Thus we need to imagine our corporeality as the repository and outcome of dispositions, forms of capital and orientations to life which bear the weight of history - for instance a history of enfeeblement as culture, deeply ingrained in women's physical dispositions.

To expose the deep embeddedness of history in our bodies and in our psyche, I used critical autobiography as 'testimony' (Ricoeur 1992). This enabled me to trace the embodied dispositions I inherited to the familial culture in which I was brought up. This inheritance had a complex history, constituted of a sedimentation of layers of effects and factors - thus understanding physical competence as natural aptitude, prioritising intellectual development and treating the body as both secondary and mindless has its roots in Cartesian thought. Furthermore norms of embodiment were brought to bear on the orientation to bodily competence but also the confidence which I started off with, before I even entered the hypermasculine world of mountaineering, with physical stasis as default. What becomes clear is that these influences have a 
temporal dimension: they predated my own lifetime by up to several centuries and they acted as a weight which slowed down progress, even as the space of possibilities was broadening.

How I was able to divest myself of this weight, or most of it, beyond the first encounter, can be conceptualised as a peeling off of layers, sometimes opportunistically, or through experience and at other times through conscious planning. The layer of opportunity lay in the encounter with two men who facilitated the introduction to mountain walking. The first time around was clearly not enough to kickstart independent engagement. I needed a second chance. But I also needed to surmount the Cartesian model of embodiment. This model takes no account of the changes in sensed experience which might over time transform how we live in and how we identify with our bodies. Although I had no obvious physical capital or family history which presaged the development of skills for mountain walking, navigating and self-sufficiency, over time, through practice, I realised that I wanted to be stronger and better. This then acted as a challenge to a reductionist and naturalised conception of feminine embodiment which eventually led to recognise that I needed to take a more instrumental approach to hillwalking: I began to treat it as a career and set progression thresholds, career targets, thus adopting a broadly linear trajectory towards the achievement of my goals. Crucially I also engaged consciously with the need for physical training and skills development, in line with emergent norms. In this way I came to embrace the new logic of practice of physical activity.

The process of destabilisation of norms of feminine embodiment was also rehearsed in internal dialogues, about diverse issues such as encouraging myself, making decisions about how much risk to take, managing any feelings of guilt about the propriety of forsaking family obligations, dealing with acute sensitivity to the possibility that others might not approve and more recently about age-appropriate physicality. This is not only part of a conscious engagement with career-making but also the manifestations of the complex emotional labour which is an intrinsic aspect of becoming a hillwalker. Surmounting these silent interdicts has been a way of giving myself permission to do what I now wish to do. What is clear however is that this process of destabilisation is unfinished - any sense of guilt or transgression continues to pervade what I do, most especially when planning outings. But there are other threats too. 
The body is fragile and liable to impaired functioning (Turner 2003). Life events can place the career at risk. More fundamental questions about the purpose of being physically active can destabilise what has been achieved (let alone even prevent the career from taking off in the first place). As I look ahead to the future, as an ageing woman, I wonder when norms of age-appropriate embodiment will catch up with me, who or what structures will enforce them and how I will manage them.

Here we can see the limitations of motivation explanations and coextensively of rigid understandings of generation. Building a hillwalking career has taken, literally, years and has entailed making sacrifices. Here motivation could very well be interpreted as obsession, selfishness or even as insensitivity to risk and normative obligations. Thus whilst I, and my age contemporaries, have benefited from the loosening of gendered norms of embodiment and, concurrently, the broadening of spaces of embodied agency, the internal dialogue is in effect legitimation work, rather than purely motivation work. In addition, as highlighted in the previous paragraph, the discursive constraints which continue to inform how we age have not been completely eliminated. Indeed, I share many of these features with my mother and her own age contemporaries. We have yet to discover how current young women will manage the weight of history in the decades ahead. Thus different times co-exist within one lifetime and generational boundaries can prove to be remarkably porous and unstable. I would suggest that the concept of generation is better used as a heuristic device, that is as a way of interrogating the potential for, and the emergence of, new forms of life. In methodological terms, the critical autobiographical approach I have chosen brought to light the legitimation work that was required to unsettle the weight of history. This approach can be used more widely for instance in life history or biographical interviews or in visual methodologies to capture agency as a process, giving people the opportunity to bear witness to the twists and turns of their lives, to locate themselves and their experiences in time and engage with sensations such as those brought on by fear, guilt, pleasure, etc. The data yielded in these research encounters become historical documents which show how agency is integrated in its broader social and cultural context. We can see clearly here that taking up physical activity is more than a problem of individual motivation. In fact framing it in those terms merely serves to demonise those who lack the correct levels of motivation. Thus what is reinforced here is the critical dimension of qualitative inquiry, already advocated by Charmaz (2016), Denzin (2015) and Flick (2016): by problematising the 
language of deficit which imbues much of the physical activity literature I have reframed the question of physically active embodiment as an opportunity for challenging oppressive discourses. The barriers to physical activity are not merely obstacles for individuals to surmount so that they can engage in health-related behaviour, but forms of oppression which reinforce inequalities of age, gender, class and others which patterns of physical activity largely reflect.

\section{References}

Adams B (1990) Time and Social Theory. Cambridge: Polity Press.

Adams TE, Holman Jones S and Ellis C (2015) Autoethnography. Oxford: Oxford University Press.

Allen-Collinson J (2010) Running embodiment, power and vulnerability: Notes towards a feminist phenomenology of female running. In: Kennedy E and Markula P (eds) Women and Exercise: The Body, Health and Consumerism. London: Routledge, 280-298.

Allen-Collinson J (2011) Intention and epoche in tension: Autophenomenography, bracketing and a novel approach to researching sporting embodiment. Qualitative Research in Sport, Exercise and Health 3(1): 48-62.

Andrews M (1999) The seductiveness of agelessness. Ageing and Society 19(3): 301318.

Archer MS (2012) The Reflexive Imperative in Late Modernity. Cambridge: Cambridge University Press.

Baars J (1991) The Challenge of Critical Gerontology: The Problem of Social Constitution. Journal of Aging Studies 5(3): 219-243.

Barral MR (1984) The Body in Interpersonal Relations: Merleau-Ponty. Lanham, MD: University Press of America.

Becker HS and Strauss A (1956) Careers, Personality, and Adult Socialization. American Journal of Sociology 62(3): 253-263.

Bourdieu P (1984) Distinction: A Social Critique of the Judgement of Taste. Cambridge, Mass: Harvard University Press.

Bourdieu P (1992) The Logic of Practice. Cambridge: Polity.

Campbell-Jack D, Hinchcliffe S and Rutherford L (2015) The Scottish Health Survey Vol 1 Main Report. Edinburgh: Scottish Government. 
Carlson, SA, Fulton, JE, Schoeborn, CE, Loustalot, F (2010) Trend and Prevalence Estimates Based on the 2008 Physical Activity Guidelines for Americans. American Journal of Preventive Medicine 39(4): 305-313.

Charmaz K (2016) The Power of Constructivist Grounded Theory for Critical Inquiry. Qualitative Inquiry.

Chisholm D (2008) Climbing like a Girl: An Exemplary Adventure in Feminist Phenomenology. Hypatia 23(1): 9-40.

Chodzko-Zajko WJ, Proctor DN, Fiatarone Singh MA, Minson CT, Nigg CR, Salem GJ, et al. (2009) Exercise and Physical Activity for Older Adults. Medicine \& Science in Sports \& Exercise 41(7): 1510-1530.

Coffey M (2003) Where the Mountain Cast its Shadow: The Personal Costs of Climbing. London: Arrow Books.

Dastur F (2001) Chair Et Langage: Essais Sur Merleau-Ponty. La Versanne: Encre Marine.

Denzin N (2015) What is critical qualitative inquiry? In: Cannella G, Pérez M and Pasque P (eds) Critical Qualitative Inquiry: Foundations and Futures. Walnut Creek, CA: Left Coast Press, 31-50.

Dionigi R (2015) Pathways to Masters Sport: Sharing Stories from Sport 'Continuers, 'Rekindler' and 'Late Bloomers'. In: Tulle E and Phoenix C (eds) Sport and Physical Activity in Later Life: Critical Perspectives. Basingstoke: Palgrave Macmillan, 54-68.

Ellis C and Bochner AP (2013) Autoethnography, Personal Narrative, Reflexivity: Researcher as Subject. In: Sikes P (ed) Autoethnography Volume 1. London: Sage, 125-173.

Flick U (2016) Challenges for a New Critical Qualitative Inquiry: Introduction to the Special Issue. Qualitative Inquiry.

Gilleard C and Higgs P (2013) Ageing, Corporeality and Embodiment. London: Anthem press.

Gray M (1991) The First Fifty: Munro-Bagging without a Beard. Edinburgh: Mainstream.

Hansen PH (2013) The Summits of Modern Man. Cambridge, Mass.: Harvard University Press.

Hawley-Hague H, Horne M, Skelton DA and Todd C (2016) Older Adults' Update and Adherence to Exercise Classes: Instructors' Perspectives. Journal of Aging and Physical Activity 24(1): 119-128. 
Heo J, Culp B, Yamada N and Won Y (2012) Promoting Successful Aging Through Competitive Sports Participation: Insights From Older Adults. Qualitative Health Research.

Hill L and Child G (2002) Climbing Free: My Life in the Vertical World. New York: W. W. Norton.

Mannheim K (1970) The Problem of Generations. The Psychoanalytic Review 57(3): 378-404.

Markula P (2003) The Technologies of the Self: Sport, Feminism and Foucault. Sociology of Sport Journal 20(2): 87-107.

Markula P (2006) Deleuze and the Body Without Organs: Disreading the Fit Feminine Body. Journal of Sports \& Social Issues 30(1): 29-44.

Mazel D (1994) Mountaineering Women: Stories by Early Climbers. College Station, TX: Texas A\&M University Press.

Mazzeo RS, Cavanagh P, Evans WJ, Fiatarone M, Hagberg J, McAuley E, et al. (1998) ACSM Position Stand: Exercise and Physical Activity for Older Adults. Medicine \& Science in Sports and Exercise 30(6): 992-1008.

Muldoon MS (2006) Tricks of Time: Bergson, Merleau-Ponty and Ricoeur in Search of Time, Self and Meaning. Duquesne University Press: Pittsburgh, Pa.

Nettleton S (2015) Fell Running in Later Life: Irresponsible Intoxication or Existential Capital? In: Tulle E and Phoenix C (eds) Physical Activity, Sport and Later Life: Critical Perspectives. Basingstoke: Palgrave Macmillan, 124-136.

Ortner SB (1999) Life and Death on Mt Everest: Sherpas and Himalayan Mountaineering. Princeton, NJ: Princeton University Press.

Ottogalli-Mazzacavallo C and Saint-Martin J (2009) Femmes Et Hommes Dans Les Sports De Montagne: Au-Delà Des Différences. Grenoble: MSH-Alpes.

Owen N, Sparling PB, Healy GN, Dunstan DW and Matthews CE (2010) Sedentary Behavior: Emerging Evidence for a New Health Risk. Mayo Clinic Proceedings 85(12): 1138-1141.

Palmer V (2015) Keeping It in the Family: The Generational Transmission of Physical Activity. In: Tulle E and Phoenix C (eds) Physical Activity, Sport and Later Life: Critical Perspectives. Basingstoke: Palgrave, 69-80.

Pilcher J (1994) Mannheim's Sociology of Generations: An Undervalued Legacy. The British Journal of Sociology 45(3): 481-495.

Popkewitz TS (2013) What's in a research project: Some thoughts on the intersection of history, social structure, and biography. In: Sikes P (ed) Autoethnography Vol. 1. London: Sage, 87-107. 
Roberts K, Minten JH, Chadwick C, Lamb KL and Brodie DA (1991) Sporting lives: a case study of leisure careers. Loisir Et Société 14(1): 261-284.

Rose N (2007) The Politics of Life itself: Biomedicine, Power, and Subjectivities in the 21st Century. Princeton: Princeton University Press.

Timonen V and Conlon C (2015) Beyond Mannheim: Conceptualising how people 'talk' and 'do' generations in contemporary society. Advances in Life Course Research 24: 1-9.

Tulle E (2008) Ageing, the Body and Social Change: Running in Later Life. Basingstoke: Palgrave.

Tulle E (2015) Physical Activity and Sedentary Behaviour: A Vital Politics of Old Age? In: Tulle E and Phoenix C (eds) Physical Activity and Sport in Later Life: Critical Perspectives. London: Palgrave.

Tulle E and Dorrer N (2012) Back from the brink: Ageing, exercise and health in a small gym. Ageing and Society 32(7): 1106-1127.

Ward Thompson C, Curl A, Aspinall P, Alves S and Zuin A (2014) Do changes to the local street environment alter behaviour and quality of life of older adults? The 'DIY Streets' intervention. British Journal of Sports Medicine 48(13): 1059-1065.

Whorton JC (1982) 'Athlete's Heart': The Medical Debate Over Athleticism, 18701920. Journal of Sport History 9(1): 30-52.

World Health Organisation (2010) Global Recommendations on Physical Activity for Health. Geneva: World Health Organisation. 